\title{
Fragilidade Financeira das Empresas não Financeiras de Capital Aberto no Brasil entre 2010 e 2016: uma Análise Setorial a partir de Minsky
}

\section{Financial Fragility of the Brazilian non-Financial Open-Capital Enterprises between 2010 and 2016: a Sectorial Analysis Inspired by Minsky}

Lilian N. Rolim ${ }^{\text {a }}$

Rafael Cattan ${ }^{\mathrm{a}}$

Jorge Antoniolia

\begin{abstract}
Resumo: O presente artigo examina a fragilidade financeira das empresas não financeiras de capital aberto no Brasil entre 2010 e 2016 a partir da tipologia proposta por Minsky (1992). Com base na metodologia de Bacic (1990), analisa-se o perfil de 19 dos 20 setores econômicos do software Economatica. É possível constatar que, para o período observado, marcado pela queda dos preços das commodities, depreciação cambial, desaceleração das economias internacional e brasileira e deterioração das fontes de financiamento, houve uma redução das firmas em posição hedge e, como contrapartida, houve um aumento de empresas especulativas e ponzi. Entretanto, há padrões setoriais específicos que sugerem que alguns setores são mais resilientes do que outros. De modo geral, existem indícios que permitem afirmar que, no período de reversão do ciclo econômico, aumentou a fragilidade financeira das empresas não financeiras de capital aberto no país.
\end{abstract}

Palavras-chave: Minsky. Brasil. Hipótese da fragilidade financeira. Empresas de capital aberto.

\begin{abstract}
The paper analyses the financial fragility of Brazilian open-capital non-financial enterprises between 2010 and 2016 according to the typology suggested by Minsky (1992). Applying the methodology from Bacic (1990), the profile of 19 of the 20 economic sectors listed by the Economatica software was analyzed. Concerning the selected period, which was characterized by the reduction of commodities prices, currency depreciation, deceleration of economic growth at the global and domestic levels, and worsening of the financial sources, it was possible to identify a reduction of firms in hedge position and an increase in the number of speculative and ponzi enterprises.
\end{abstract}

\footnotetext{
* $\quad$ Agradecemos à Nathalie Marins, Rodrigo Lanna e Miguel Bacic pelos comentários e sugestões. LNR agradece ao Conselho Nacional de Desenvolvimento Científico e Tecnológico (CNPq) pelo apoio financeiro (processo \# 131651/2015-3).

Universidade Estadual de Campinas (UNICAMP), Instituto de Economia (IE), Programa de Pós-Graduação em Economia. Campinas, São Paulo, Brasil
} 
However, there are specific sectorial patterns that suggest that some sectors are more resilient than others. This analysis supports the conclusion that, during the reversal of economic cycle, the overall financial fragility of open-capital enterprises increased.

Keywords: Minsky. Brazil. Financial instability hypothesis. Open capital enterprises.

JEL Classification: E12; E32; G3.

\section{Introdução}

A instabilidade das economias capitalistas é objeto de escrutínio por diversos autores e, ao longo do tempo, levou ao desenvolvimento de inúmeras teorias. Em particular, a contribuição de Minsky (1994) sugere a importância do sistema financeiro para a explicação da instabilidade do sistema econômico. A partir de uma tipologia de perfis de fragilidade financeira, o autor argumenta que o aumento da participação de empresas com perfil financeiro mais frágil pode levar a um aumento da fragilidade da economia como um todo e desencadear uma crise econômica.

A hipótese de instabilidade financeira (HIF) desenvolvida pelo autor sugere que, ao longo do ciclo econômico, as empresas tomam posições cada vez mais arriscadas, muitas vezes devido ao cenário geral de euforia nos períodos de maior crescimento e pela necessidade de financiar o crescente volume de investimento com capital de terceiros. Com isso, haveria um aumento da proporção de empresas em situação financeira mais frágil e a percepção dessa maior fragilidade, junto ao aumento da taxa de juros pelo Banco Central, eventualmente levaria a uma reversão das expectativas e do ciclo econômico.

A partir desse arcabouço teórico, o objetivo deste artigo é verificar como evoluiu a fragilidade financeira das empresas não financeiras de capital aberto no Brasil entre 2010 e 2016. Desse modo, busca-se avaliar até que ponto a correlação sugerida por Minsky se aplica ao contexto do país no sentido de haver um padrão cíclico da fragilidade financeira das empresas não financeiras. Em especial, investiga-se se houve maior fragilidade financeira diante da desaceleração econômica e o consequente comprometimento dos fluxos de caixa dessas empresas. Ademais, como uma forma de contribuir para o entendimento dessa dinâmica no país, busca-se identificar padrões setoriais de fragilidade financeira a partir de dados disponibilizados no software Economatica. $\mathrm{O}$ artigo complementa, desse modo, análises como as de Almeida, Novais e Rocha (2016) e Corrêa, Lemos e Feijo (2017), nas quais mudanças no padrão de financiamento das empresas não financeiras brasileiras desde 2010 são relacionadas a uma maior fragilidade financeira no momento de reversão do ciclo econômico, trazendo efeitos deletérios sobre a acumulação de capital. 
O trabalho está estruturado em mais quatro seções, além desta introdução: na segunda, define-se a HIF e ilustra-se a tipologia sugerida por Minsky (1992); na terceira, discute-se a estrutura de financiamento de uma amostra de corporações brasileiras para o período de 2004 a 2016, destacando-se a composição do financiamento do investimento, sua evolução no tempo e alguns indicadores tradicionais de endividamento e solvência; na quarta, apresenta-se a principal contribuição do artigo, discutindo o contexto da economia brasileira no período, a metodologia e os resultados obtidos; para finalizar, a quinta seção apresenta as considerações finais do trabalho.

\section{A Contribuição Teórica de Minsky}

Esta seção apresenta brevemente o arcabouço teórico deste artigo, discutindo a HIF de Minsky e apresentando a tipologia de fragilidade financeira das firmas a partir da análise de sua estrutura de passivos e ativos.

\subsection{A Hipótese da Instabilidade Financeira}

A partir da eclosão da bolha imobiliária nos Estados Unidos - que culminou na crise financeira global de 2007-2008 e cujos impactos se mostram, anos depois, ainda presentes -, intensificou-se o interesse pela economia keynesiana nas discussões econômicas (BLECKER, 2016). Dentre os motivos para tal, pode-se enfatizar a contribuição dessa abordagem à explicação do impacto da demanda agregada sobre os níveis de produto e emprego, bem como a relevância da moeda como elemento determinante das decisões dos agentes em sua análise. Uma das formulações teóricas revisitadas nesse contexto foi a HIF do economista estadunidense Hyman Minsky.

A despeito de ter sofrido modificações ao longo de tempo (LOURENÇO, 2006), essa hipótese tem como argumento central a ideia de que, em economias capitalistas modernas com mercados financeiros sofisticados, períodos de estabilidade se alternam com períodos de instabilidade do sistema. Além disso, esses ciclos de crescimento e crise são entendidos como processos endógenos à própria dinâmica do capitalismo moderno, visto que a própria estabilidade do sistema valida uma maior aceitação de risco por parte dos agentes tomadores de crédito, induzindo posições financeiras mais frágeis que, se analisadas de forma sistêmica, resultam em uma maior probabilidade de uma crise financeira (MINSKY, 1994).

Esse processo pode ser descrito da seguinte forma: as decisões de investimento são, essencialmente, decisões especulativas, visto que se pautam em expectativas acerca do fluxo de receitas que será gerado pelo investimento. À medida que se aumenta o nível de investimento, a necessidade de endividamento das 
firmas também aumenta, sobretudo no caso das firmas não financeiras. Nesse processo, os agentes tendem a assumir posturas financeiras cada vez mais especulativas, pois, com o crescimento da economia, os agentes se veem mais otimistas e isso interfere tanto na avaliação dos rendimentos esperados, quanto na aceitação de níveis mais elevados de endividamento (o que também é influenciado pelo boom no mercado de ações, que eleva o valor de mercado das firmas). ${ }^{1}$ De modo semelhante, os bancos percebem essas dívidas como oportunidades de ampliar seus lucros, o que os incentiva a realizar inovações financeiras para ampliar os empréstimos a despeito da regulação bancária em voga. Quando se evidencia o excessivo grau de alavancagem financeira dos agentes e as expectativas se revertem, a readequação das posições financeiras dos agentes e o aumento dos requerimentos dos bancos para concessão de crédito levam a uma crise sistêmica. ${ }^{2}$

É nesse sentido que, mediante a introdução da análise da alavancagem financeira dos agentes e sua estrutura de passivo, ${ }^{3}$ Minsky (1992) vincula o portfólio das unidades econômicas ao processo de investimento. Assim, as decisões de investimento dos agentes econômicos, que refletem as expectativas de retorno, passam a envolver decisões de como financiar esse gasto, o que leva a uma determinada estrutura do passivo. O autor observa que, enquanto o fluxo de saída associado aos compromissos financeiros assumidos por sua estrutura de passivo é pré-determinado e certo, o retorno dos investimentos, medido por seu fluxo de entrada futuro, é esperado e, portanto, sujeito à incerteza inerente à realização de lucros futuros por parte das firmas. A relação entre um fluxo de saída efetivo e um fluxo de entrada sujeito a incertezas eleva o caráter especulativo do investimento e

$1 \quad$ Esta ideia é relativizada por Lavoie e Seccareccia (2001, p. 77, tradução própria) já que, segundo os autores, a hipótese de fragilidade financeira de Minsky "[...] recai sobretudo em uma construção microeconômica que talvez seja melhor cristalizada em sua famosa representação gráfica da decisão de investimento da empresa. Sob o pressuposto estrito de um determinado nível de fundos internos, o maior investimento que seria associado a expectativas empresariais mais otimistas deve inevitavelmente resultar em maiores taxas de endividamento e alavancagem. Nossa opinião é que os índices de alavancagem poderiam aumentar tanto quanto poderiam diminuir durante uma expansão econômica. Tudo depende do que está acontecendo com parâmetros como a política da taxa de juros do banco central e o comportamento dos déficits governamentais. Proporções de dívida mais elevada não são uma consequência necessária do maior investimento empresarial."

2 Essa readequação se dá porque o comportamento dos bancos não é de passivamente sancionar a demanda por crédito: a partir de certo momento, irão ampliar as taxas de juros para compensar o risco crescente, dado que passaram a aceitar menores margens de segurança. Pelo efeito da taxa de juros sobre o investimento, pode-se chegar a uma reversão em que cessa o investimento macroeconômico. Nessa situação, partindo da análise kaleckiana de que os lucros são função do investimento (KALECKI, 1983), os lucros brutos cairão e as firmas terão dificuldades para cumprir seus compromissos financeiros. Estas terão de vender seus ativos para pagar suas dívidas, o que leva a uma situação de deflação de preço de ativos e uma crise sistêmica.

3 Essa análise é fundamental na obra de Minsky, principalmente pelo fato de vincular as instituições financeiras, mais precisamente os bancos, como organizações lucrativas através da gestão e gerenciamento dos passivos no processo de intermediação financeira. Essa perspectiva contrasta com a visão particular dos bancos promulgada pela Teoria Quantitativa da Moeda (MINSKY, 1992). 
abre a possibilidade de que as empresas apresentem diferentes graus de fragilidade financeira, que refletem suas estruturas de passivos e ativos.

Assim, a teoria de Minsky enfatiza o papel dos ativos e dos passivos previamente assumidos para o financiamento do investimento na determinação dos ciclos econômicos e dos momentos de crise. Dessa forma, crises financeiras deixam de ser compreendidas como resultado de choques exógenos ou ações irracionais e tornam-se movimentos internos à própria dinâmica capitalista moderna, na qual fica evidente a sinergia entre os mercados financeiro e monetário e o lado real da economia.

Portanto, é essencial, para a análise da fragilidade financeira da economia, o entendimento das posições financeiras de seus agentes. Para tanto, Minsky (1992) propõe uma tipologia, apresentada na próxima seção, que permite classificar as empresas de acordo com seu grau de fragilidade financeira.

\subsection{A Tipologia das Empresas}

A discussão anterior indica a importância da análise da estrutura de passivos e ativos das empresas na determinação de sua fragilidade financeira. Com a finalidade de mensurar o grau dessa fragilidade financeira, Minsky (1992) propõe uma análise dos fluxos de caixa de forma a identificar três tipos de perfis de firmas: hedge, especulativo e ponzi.

Segundo essa tipologia, as firmas hedge são aquelas que podem cumprir a totalidade de compromissos financeiros assumidos a partir do fluxo de caixa: o retorno esperado de seu investimento é maior do que as obrigações financeiras associadas à dívida contraída para financiá-lo em todos os períodos. Assim, as empresas com postura financeira hedge só têm como restrição o funcionamento normal do mercado de fatores e produtos e só podem ter seu perfil de fragilidade financeira ameaçado em caso de crises nesses mercados.

De modo distinto, as estruturas especulativas apresentam um maior grau de fragilidade financeira devido, essencialmente, a um descasamento entre prazos de recebimento e pagamentos em alguns períodos. Essas firmas têm a necessidade de contrair novas dívidas para cumprir os compromissos de pagamento do principal, dado que o fluxo de caixa gerado só é suficiente para saldar os juros e uma parte do principal. Assim, firmas especulativas terão que renegociar suas dívidas e assumir novos passivos. Logo, para seu funcionamento normal, firmas nessa situação dependem do funcionamento normal do mercado de crédito e do mercado de fatores e produtos. É interessante destacar que Minsky (1992) identifica, como entidades especulativas típicas da economia capitalista, os governos e os bancos.

Por fim, no caso das firmas em situação ponzi, o fluxo de caixa gerado por suas operações é insuficiente para saldar até mesmo os juros das dívidas contraídas, de forma que haverá capitalização dos juros e principal no seu passivo. Por 
essas razões, as firmas em situação ponzi devem vender ativos ou tomar novos empréstimos. Porém, Minsky (1992) adverte que as duas opções podem elevar o risco de deterioração de sua situação patrimonial, visto que o aumento do estoque de dívida ou redução de seus ativos reduziria a margem de segurança dos seus credores. Consequentemente, as unidades ponzi são extremamente dependentes do funcionamento adequado do mercado financeiro porque necessitam refinanciar seu passivo, e as variações positivas nas taxas de juros terão um impacto negativo em sua situação financeira, elevando o custo de seu passivo e potencialmente forçando a liquidação de seus ativos (MINSKY, 1992).

Minsky (1992) destaca que não é a situação de uma empresa em particular que eleva o risco sistêmico na economia, mas a relação entre o conjunto das instituições que atuam no sistema financeiro e suas distintas posições patrimoniais no tempo que pode levar ao desenvolvimento de crises endógenas. ${ }^{4}$ Dessa forma, segundo Minsky, se existe uma dominância de estruturas hedge no sistema financeiro, isso tende a contribuir para a estabilidade da economia. Por outro lado, quanto maior a proporção relativa de estruturas ponzi, maior a probabilidade de instabilidade econômica. Ademais, o autor sugere que a economia transita de regimes financeiros estáveis para regimes financeiros instáveis de acordo com a capacidade das entidades financiadas de gerenciar o seu portfólio e honrar os compromissos assumidos a partir do fluxo de caixa operacional.

A dinâmica do sistema econômico, portanto, é intrinsecamente ligada às decisões de composição de portfólio das empresas e bancos. Estas, em conjunto com o funcionamento do mercado real, são responsáveis pela mudança de uma situação de menor para uma de maior fragilidade financeira do sistema. Como a assunção de passivos está ligada ao otimismo dos agentes em relação aos retornos esperados dos investimentos, e esse otimismo aumenta nos períodos de estabilidade, tem-se a ideia fulcral de Minsky (2008) de que a estabilidade é desestabilizadora.

A partir dessa tipologia elaborada por Minsky, as próximas seções analisam como a fragilidade financeira das empresas brasileiras não financeiras de capital aberto se modificou num período de desaceleração econômica, quando o menor crescimento levou a uma reversão de expectativas e, possivelmente, a fluxos de entrada menores do que os esperados quando se assumiram os fluxos de saída associados aos passivos. Esse período também trouxe alterações no padrão de fi-

4 Aqui, é importante notar que o comportamento das firmas não financeiras se difere em grande medida das firmas financeiras na dinâmica dos ciclos de crédito e crescimento, seguido dos momentos de crise e ajustamento (deflação de ativos e débitos). Mais precisamente, a contrapartida do aumento do endividamento e crescimento do passivo das firmas não financeiras nos momentos de boom é o crescimento do ativo por parte das firmas financeiras, cujo comportamento é pró-cíclico. Por outro lado, as firmas não financeiras tendem a acumular passivos no momento de crescimento em virtude da necessidade de financiamento do investimento. Ver Borio, Furfine e Lowe (2001) a esse respeito. 
nanciamento do investimento e em seu custo por causa das alterações das taxas de câmbio e de juros, afetando a estrutura de passivo das empresas.

$\mathrm{Na}$ próxima seção, ilustra-se o comportamento do financiamento das empresas, identificando-se possíveis modificações em seu comportamento ao longo do período em questão. Essa investigação dá subsídios à análise posterior dos padrões de fragilidade financeira da economia brasileira no período.

\section{Financiamento das Empresas Brasileiras no Período de 2004 a 2016}

Esta seção analisa o padrão de financiamento do investimento das empresas brasileiras, de modo a indicar possíveis mudanças que alteram a composição de seu passivo. Além da análise do padrão de financiamento, alguns indicadores agregados de solvência financeira e endividamento também são analisados com o intuito de fornecer uma primeira caracterização da exposição financeira das firmas neste período.

\subsection{Padrão de Financiamento do Investimento}

A análise da segunda seção mostra que Minsky, ao explorar a relação entre os ciclos econômicos e a composição do balanço patrimonial das empresas em nível microeconômico, mostrou a importância da estrutura dos passivos na determinação da dinâmica do lado real da economia. A forma de financiamento das firmas, em particular, está diretamente ligada à sua exposição tanto a flutuações no mercado financeiro quanto aos ciclos econômicos. Nesta seção, busca-se analisar o lado financeiro a partir do financiamento do investimento no Brasil entre 2004 e 2016. Opta-se por esse período, que é mais longo que o da caracterização das empresas de acordo com a tipologia de Minsky realizada na seção 4, porque permite a análise de mudanças no padrão de financiamento em momentos distintos do ciclo econômico.

A partir de uma análise das fontes de financiamento do investimento de empresas e famílias no país entre 2004 e 2016, o relatório do Centro de Estudos do Mercado de Capitais $(2017 a)^{5}$ indica que aproximadamente metade do investi-

5 As categorias são definidas da seguinte forma: a) investimento estrangeiro direto: recurso próprio das empresas estrangeiras; b) recursos próprios: lucros retidos e poupança interna; c) BNDES: desembolsos para financiamentos a empreendimentos e máquinas e equipamentos; d) habitacional: desembolsos do Fundo de Garantia do Tempo de Serviço (FGTS) em financiamentos à produção habitacional (construção e reforma) e saneamento e desembolsos do Sistema Brasileiro de Poupança e Empréstimo (SBPE) em financiamentos à produção habitacional (construção e reformas); e) mercado externo: emissões externas (bond e notes) de empresas não financeiras pela taxa de câmbio média; f) mercado de capitais: emissão primária de ações e títulos de dívida privada (debêntures de empresas não financeiras e certificados de recebíveis imobiliários); g) ações: emissão primária de ações. 
mento nacional foi financiado com recursos próprios. Em segundo lugar, encontra-se o investimento direto estrangeiro (IDE), com participação de 19\% no total dos recursos, seguido do crédito do Banco Nacional de Desenvolvimento Econômico e Social (BNDES) (12\%), de recursos do mercado de capitais (7\%), de emissões no mercado externo (5\%), do crédito habitacional (5\%) e, por fim, do mercado de ações (2\%), como mostra o Gráfico 1.

Gráfico 1 - Fontes de financiamento: média de 2004 a 2016 (\% do total)

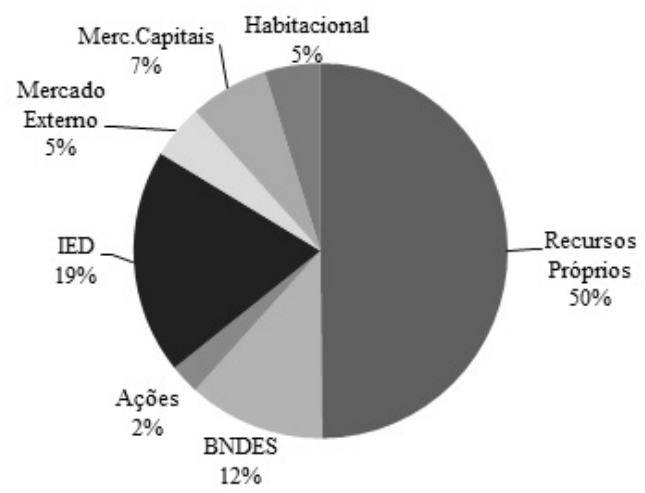

Fonte: Elaboração própria a partir de Centro de Estudos do Mercado de Capitais (2017a).

Duas observações merecem destaque nessa análise. Em primeiro lugar, esse valor é uma média, não captando a trajetória de cada uma dessas fontes ao longo do período. Em segundo lugar, há grande diferença no padrão de financiamento com relação ao tipo de empresa, sobretudo a depender de seu tamanho e setor. Almeida et al. (2013), por exemplo, mostram que, enquanto a indústria de construção, que tem peso importante na economia nacional, financiou-se, entre 2004 e 2007, com $12 \%$ de lucros retidos, ${ }^{6}$ o segmento "comércio (diversos)" se financiou totalmente pela mesma fonte.

Ademais, é importante levar em consideração que, ao mesmo tempo que pode haver dispersão nos meios de financiamento em função do tamanho e natureza da firma, o próprio padrão pode se modificar ao longo do tempo. Levando-se em consideração o papel do custo financeiro de cada estratégia de financiamento, como discutido na seção anterior, espera-se que ocorra uma mudança no perfil de financiamento das empresas ao longo do ciclo econômico, seja por restrições pelo lado da oferta de crédito, seja por choques pelo lado da demanda, fenômeno

$\overline{6 \text { Valor referente }}$ ao percentual de financiamento sobre a variação do ativo total menos a variação do passivo circulante. 
identificado pela literatura. ${ }^{7} \mathrm{O}$ Gráfico 2 ajuda a analisar a dinâmica das diferentes fontes do financiamento durante esse período.

Gráfico 2 - Fontes de financiamento do investimento (\% do total)

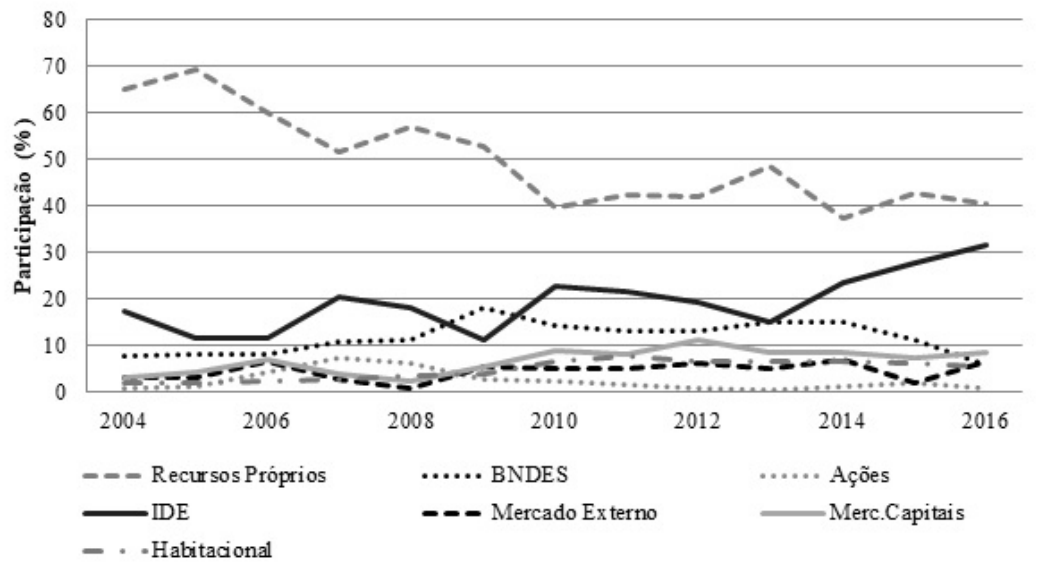

Fonte: Elaboração própria a partir de Centro de Estudos do Mercado de Capitais (2017a).

Nota-se que, apesar de ter a maior participação relativa como fonte de financiamento do investimento, os recursos próprios têm trajetória declinante, enquanto o IDE ganha maior peso relativo, sobretudo a partir de 2013. ${ }^{8}$ Em relação ao IDE, cabe ressaltar que, ainda que tenha ganhado importância relativa e absoluta em 2013 e 2014, deve-se ressalvar o efeito câmbio sobre a participação dessa fonte de recurso nos anos seguintes. Analisando-se a série em dólares, verifica-se que houve redução no valor absoluto de IDE após 2010 (BANCO CENTRAL DO BRASIL, 2018), o que relativiza sua importância na composição do financiamento do investimento após a crise de 2008 (a despeito da breve recuperação em 2010). Essa redução do valor do IDE em dólares após 2010 contrasta com sua trajetória geral de crescimento nos anos 2000 (a despeito de pontuais reduções em alguns anos, em especial em 2009).

O Gráfico 2 indica que, entre 2004 e 2016, a participação dos recursos próprios se reduziu em mais de 37 p.p., colocando-os, junto ao crédito do BNDES cuja redução foi de 24 p.p. no mesmo período -, entre as fontes de financiamento que apresentaram as quedas mais significativas (CENTRO DE ESTUDOS DO MERCADO DE CAPITAIS, 2017a). Dentre as hipóteses explicativas desse fenômeno,

$7 \quad$ Ver Basset et al. (2014).

8 Esse valor inclui empréstimos intracompanhia, em acordo com o Manual de balanço de pagamentos e posição internacional do investimento (BPM6) do FMI, o que influenciou esse resultado. Para esclarecimento metodológico, ver nota do Banco Central do Brasil disponível no link: https:// www.bcb.gov.br/ftp/infecon/nm3bpm6p.pdf. Acesso em: 04 de março de 2018. 
destacam-se: o quadro de desaceleração e recessão da economia a partir de 2011, que, reduzindo o lucro retido das companhias, limitou suas fontes internas de financiamento e uma mudança na orientação da política do BNDES, concomitante à própria redução da demanda por crédito da economia (BANCO NACIONAL DE DESENVOLVIMENTO ECONÔMICO E SOCIAL, 2017). Vale notar que essa mudança no papel do principal banco de desenvolvimento do país se tornou evidente no biênio recessivo (2015-2016), quando a sua participação no financiamento total passou de 15,2\% em 2014 para 6,1\% dois anos depois.

Pelo lado das fontes de financiamento que apresentaram maior crescimento de sua participação relativa, destacam-se o crédito habitacional, cujo peso na composição do financiamento cresceu $10 \%$ ao ano no período, seguido do financiamento pelo mercado de capitais ( $9,3 \%$ a.a.), do mercado externo (6,6\% a.a.) e do IDE (5,5\% a.a.). Nota-se, também, que, enquanto o crédito habitacional cresceu de forma significativa após a crise de 2008 e manteve seu peso relativo desde então, a captação externa e, sobretudo, o IDE tiveram crescimento expressivo a partir de 2014, quando se iniciou a recessão técnica no país. ${ }^{9}$ De fato, dentre as hipóteses explicativas para o maior peso da captação externa, destacam-se uma reação das firmas à forte desaceleração da atividade econômica doméstica, o baixo patamar de juros básicos externos, a mudança na orientação da política do financiamento público e, ainda, a mudança metodológica da contabilidade do IDE.

Assim, levando-se em consideração que a redução da capacidade de financiamento com recursos próprios levou ao aumento da procura por recursos externos, pode-se inferir que as empresas brasileiras elevaram sua exposição ao risco cambial, caracterizando um processo comum de vulnerabilidade externa de economias em desenvolvimento (BODNAR; MARSTON, 2002). Apesar desse risco ser atenuado no caso de empréstimos intercompanhias, há evidências de aumento da exposição das firmas nacionais, intensificada pela dinâmica da taxa de câmbio no período (ver seção 4.1).

\subsection{Indicadores de Fragilidade Financeira}

A análise do padrão de financiamento do investimento ajuda a compreender a potencial exposição patrimonial das empresas. No entanto, o padrão de financiamento é apenas o primeiro passo para um entendimento mais completo da fragilidade financeira das empresas analisadas. O segundo passo da análise é a avaliação de indicadores de endividamento e capacidade de pagamento, que, neste trabalho, complementam a análise baseada no trabalho de Minsky, proposta nas próximas seções.

9 Ainda que não exista um consenso em torno da definição de recessão, define-se recessão técnica como dois trimestres consecutivos de queda no PIB (CALLEN, 2008). 
Pelo lado do endividamento, o estudo do CEMEC (CENTRO DE ESTUDOS DO MERCADO DE CAPITAIS, 2017b), que tem como amostra 1.349 empresas de capital aberto e fechado entre 2010 e 2017, mostra que houve uma deterioração em diversos indicadores no período. Por exemplo, enquanto a relação da dívida financeira líquida sobre o indicador de lucros antes de juros, impostos, depreciação e amortização (Ebtida) era de 1,44, em 2010, em 2015 o indicador elevou-se para 3,26, reduzindo-se para 2,37 em 2016. Corroborando a análise do padrão de financiamento, o percentual de dívida em moeda estrangeira cresceu no mesmo período, saindo de 22,6\% da dívida total, em 2010, para 29,4\% em 2016. Conjuntamente, esses dados revelam tanto uma piora em termos de volume da dívida, quanto em termos de qualidade da dívida, visto que há maior exposição ao risco cambial.

No que diz respeito à capacidade de pagamento das empresas, ou seja, a relação entre o custo dessa dívida e a geração de recursos, a situação da amostra também mostrou sinais de piora entre 2010 e 2017 (CENTRO DE ESTUDOS DO MERCADO DE CAPITAIS, 2017b). Dentre os indicadores utilizados, percebe-se que a relação Ebtida sobre a despesa financeira reduziu-se significativamente no período, caindo de 2,55, em 2010, para 1,52 em 2016. O Gráfico 3 ilustra isso, apresentando a dinâmica de dois indicadores: Ebtida sobre despesa financeira e dívida financeira líquida sobre Ebtida.

Gráfico 3 - Indicadores de endividamento e capacidade de pagamento

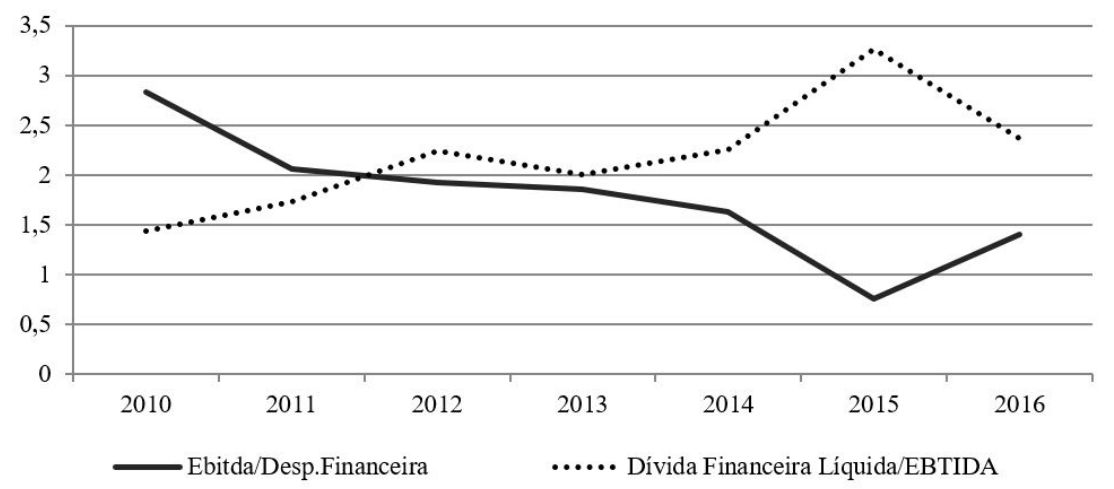

Fonte: Elaboração própria a partir de Centro de Estudos do Mercado de Capitais (2017b).

Como é possível notar, o aumento do endividamento é acompanhado pela redução da capacidade de pagamento dessa dívida, sobretudo até 2015 , visto que, em 2016, ambos indicadores voltam a melhorar. De fato, o crescimento simultâneo da dívida agregada e de seu custo relativo acompanha a trajetória declinante da demanda nacional, visto que tanto a taxa de crescimento do consumo quanto a do investimento agregados desaceleram, especialmente a partir de 2012, até se 
tornarem negativas no período recessivo (a partir do segundo trimestre de 2014 até o último trimestre de 2016).

Esse processo de deterioração da posição financeira das firmas não financeiras, sobretudo a partir de 2010, indica não apenas um aumento no seu grau de fragilidade, mas também reflete o processo histórico de financeirização da economia nacional desde a abertura econômica, conforme destacam Corrêa, Lemos e Feijo (2017). Segundo os autores, esse processo se refletiu também na mudança do padrão de financiamento do investimento, que, ao aumentar a exposição das firmas não financeiras no período de crescimento, contribuiu para uma desaceleração ainda mais acentuada no momento de reversão.

Assim, há um quadro de relativa deterioração da posição patrimonial das empresas brasileiras, concomitante à redução de sua capacidade de geração de recursos face ao maior custo de seu financiamento. Segundo a análise minskyana, essa deterioração estaria relacionada à maior fragilização financeira das firmas e, em última instância, ao próprio ciclo econômico do país. Assim, na próxima seção, busca-se entender como evoluiu o perfil de fragilidade financeira das empresas não financeiras de capital aberto no país frente às mudanças descritas na presente seção.

\section{Fragilidade Financeira das Empresas Brasileiras não Financeiras de Capital Aberto}

Esta seção traz uma breve contextualização da economia brasileira no período analisado. Posteriormente, é apresentada a metodologia utilizada e os resultados da análise para a amostra selecionada.

\subsection{Contextualização}

No período analisado, houve evidente desaceleração da economia brasileira, culminando numa forte recessão em 2015 e 2016. Ainda que o país tenha mantido elevada taxa de crescimento em 2010, indicando uma recuperação após a modesta recessão em 2009, a partir do ano de 2011 o PIB do país passa a crescer em um ritmo menor. Enquanto a taxa de crescimento média do PIB, segundo os dados do IBGE (2018), no segundo governo Lula (2007-2010) foi de 4,6\% ao ano (considerando os dois governos Lula, foi de $4,0 \%$ ao ano), a média da taxa de crescimento do PIB nos governos Dilma (2011-2016) foi de 0,4\% ao ano, com um crescimento negativo em 2015 e 2016.

De acordo com Barbosa (2013), o governo Dilma inicia-se dando continuidade às ações restritivas do final do governo Lula. Em meio a um cenário de desaceleração de outros países e início do movimento de queda dos preços das com- 
modities, o impacto negativo das medidas restritivas do início do governo Dilma foi intensificado.

Ademais, o governo Dilma trouxe uma mudança na forma de intervenção do governo, que enfrentava o desafio de readequar o modelo de crescimento ao cenário internacional mais desafiador ao país. De fato, Mello e Rossi (2017) argumentam que, a partir de 2011, o governo apostou em políticas do lado da oferta que buscavam elevar a rentabilidade do investimento privado, criando uma estratégia industrializante. A elaboração de tal estratégia se deu pelo entendimento de que o enfrentamento da questão industrial seria crucial para o prosseguimento do processo de crescimento econômico. Entretanto, apesar do enfrentamento de Dilma às altas taxas de juros e ao câmbio apreciado, Mello e Rossi (2017) argumentam que sua estratégia não logrou sucesso, pois não reverteu os entraves estruturais, a volatilidade cambial e a elevada taxa de juros de forma permanente. Ademais, a política de austeridade implementada em seu segundo mandato teria contribuído para a recessão econômica de 2015 e 2016.

Portanto, o contexto econômico do período analisado tornou-se mais desafiador às empresas brasileiras, dado o menor dinamismo econômico em relação à década anterior. Combinado à instabilidade cambial e ao aumento da taxa de juros nominal desde 2013 (ver Gráfico 4), esse contexto pode ter desencadeado um processo de crescimento da fragilidade financeira das empresas brasileiras pela dificuldade de sustentação do lucro agregado e pelas piores possibilidades de financiamento do investimento, conforme já indicado na seção anterior.

Gráfico 4 - Taxa de câmbio e taxa Selic (2010 a 2016)

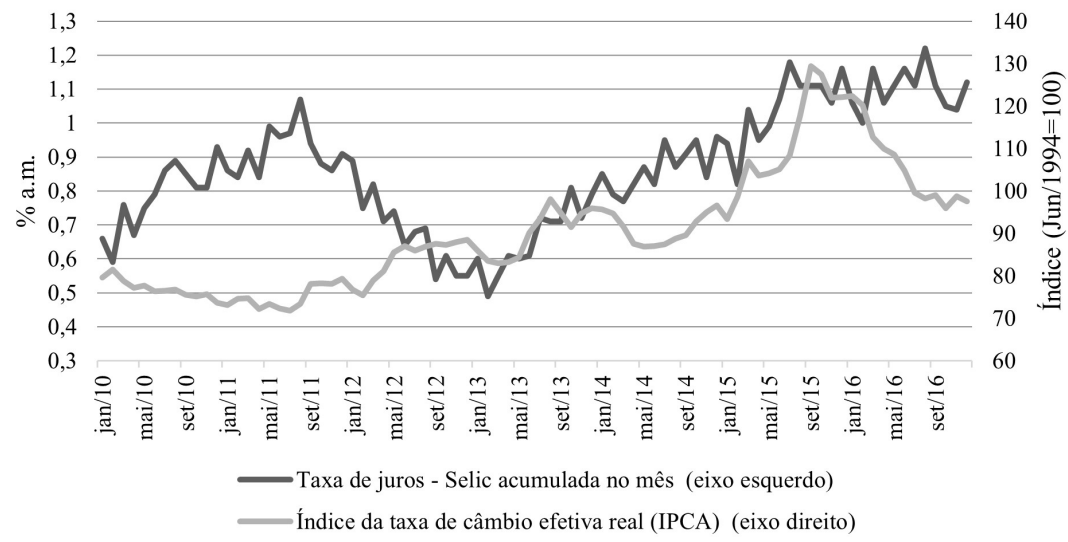

Fonte: Elaboração própria a partir de Banco Central do Brasil (2018).

De fato, diversas contribuições na literatura identificam padrões de uma crise à la Minsky neste período da economia brasileira. A crescente parcela de 
empresas que não geravam caixa suficiente para cobrir suas despesas financeiras, chegando à metade do total em 2016 (CENTRO DE ESTUDOS DO MERCADO DE CAPITAIS, 2016), é interpretada como um indicativo de que essas empresas estariam em situação ponzi (CORRÊA; LEMOS; FEIJO, 2017; PAULA, 2017). Isso seria resultado da recessão - que reduziu as vendas - do elevado endividamento de 2010 a 2016 e da elevação da taxa de juros e da taxa de câmbio (ALMEIDA; NOVAIS; ROCHA, 2016; CENTRO DE ESTUDOS DO MERCADO DE CAPITAIS, 2016; CORRÊA; LEMOS; FEIJO, 2017). Para Paula (2017), o comportamento do setor bancário frente a essa situação teria levado a um credit crunch, o que contribuiu para piorar a situação. Já para Rezende (2016, p. 15), com a impossibilidade de sustentação do lucro agregado e das expectativas de lucratividade, houve uma queda do preço de demanda do capital abaixo de seu preço de oferta, desencadeando uma queda do investimento.

Como visto, de acordo com a teoria minskiana, o contexto de menor crescimento diminui a possibilidade de sustentação do lucro agregado e, assim, pode elevar a fragilidade financeira das empresas. Na seção 4.3, analisa-se a evolução do perfil financeiro das empresas no contexto de desaceleração econômica e de deterioração das fontes de financiamento seguindo a metodologia proposta na próxima seção.

\subsection{Metodologia}

A metodologia utilizada é baseada em Bacic (1990). Seguindo-se a classificação de Minsky, assume-se que uma empresa está em situação hedge quando os fundos gerados são suficientes para pagar todos seus compromissos financeiros, em situação especulativa quando pode pagar apenas a totalidade dos juros, mas não a amortização completa, e em situação ponzi quando não pode pagar nem a totalidade dos juros. ${ }^{10}$ Esquematicamente, tem-se os seguintes perfis financeiros:

a) hedge: $F / S \geq 1$;

b) especulativo: $\mathrm{F} / \mathrm{S}<1$ e F / J $\geq 1$;

c) ponzi: $\mathrm{F} / \mathrm{S}<1$ e F $/ \mathrm{J}<1$

onde $F$ denota os fundos gerados, $J$ os juros, A representa o valor das amortizações e $S=J+A$ é o total de compromissos financeiros. Os dados utili-

10 Uma metodologia alternativa, ainda que bastante semelhante à de Bacic (1990), é a metodologia utilizada por Almeida, Novais e Rocha (2016). Os autores utilizam uma amostra homogênea do Economatica para o período de 2010 a 2015 e investigam a fragilidade financeira da economia brasileira, bem como os perfis setoriais. A principal diferença em relação a esse estudo é a caracterização do perfil especulativo, que expressa situações nas quais "[...] as receitas financeiras sobrepõem-se ao volume de despesas financeiras [...]” (ALMEIDA; NOVAIS; ROCHA, 2016, p. 31). A opção adotada no presente estudo mostra-se mais próxima à tipologia apresentada por Minsky. 
zados para determinar o perfil financeiro das empresas foram obtidos no software Economatica. ${ }^{11}$

De acordo com a disponibilidade dos dados, ${ }^{12}$ analisa-se o período de sete anos entre 2010 e 2016 para 19 dos 20 setores do Economatica. ${ }^{13}$ Assim, a amostra utilizada consiste nas empresas incluídas no software Economatica e listadas nos setores apresentados no Quadro 1. Para o ano de 2016, o total de empresas não financeiras com informações suficientes para a definição de seu perfil financeiro foi de 343, mas esse número varia para cada ano de acordo com as informações disponíveis na base de dados.

Quadro 1 - Total de empresas incluídas por setor em 2016

\begin{tabular}{|l|l|l|l|}
\hline Agro e pesca & 4 & Papel e celulose & 5 \\
Alimentos e bebidas & 14 & Petróleo e gás & 8 \\
Comércio & 22 & Química & 10 \\
Eletroeletrônicos & 24 & Siderurgia e metalurgia & 19 \\
Energia elétrica & 4 & Software e dados & 5 \\
Máquinas industriais & 55 & Telecomunicações & 11 \\
Mineração & 5 & Têxtil & 19 \\
Minerais não metálicos & 5 & Transporte e serviços & 20 \\
Outros & 3 & Veículos e peças & 14 \\
\hline
\end{tabular}

Fonte: Elaboração própria a partir do software Economatica.

\subsection{Caracterização das Empresas Brasileiras pela Tipologia de Minsky}

Apesar da impossibilidade de se realizar uma comparação com o período de crescimento em ritmo acelerado que antecede 2011 pela indisponibilidade de dados, é possível apontar uma relação entre a evolução do perfil financeiro das empresas de capital aberto e o contexto de reversão do ciclo econômico no Brasil, conforme apontado pela HIF de Minsky, a partir da análise do período de 2010 a 2016. Desse modo, o Gráfico 5 relaciona a porcentagem de empresas em cada perfil financeiro com a taxa de crescimento do PIB entre os anos 2010 e 2016.

11 Para a série de juros, utilizou-se a despesa financeira e, para a amortização, os financiamentos pagos. Os fundos gerados foram obtidos pela soma do Ebitda e receita financeira, descontando-se o imposto de renda e contribuição social a pagar.

12 Os dados de imposto de renda e contribuição social a pagar passaram a ser disponibilizados na base Economatica apenas a partir de 2010, em adequação à Lei n ${ }^{\circ} 11.638$.

13 O setor de finanças e seguros não foi incluído devido às suas peculiaridades em relação aos demais setores. Assim, a amostra inclui as empresas não financeiras com informações disponibilizadas no Economatica. 


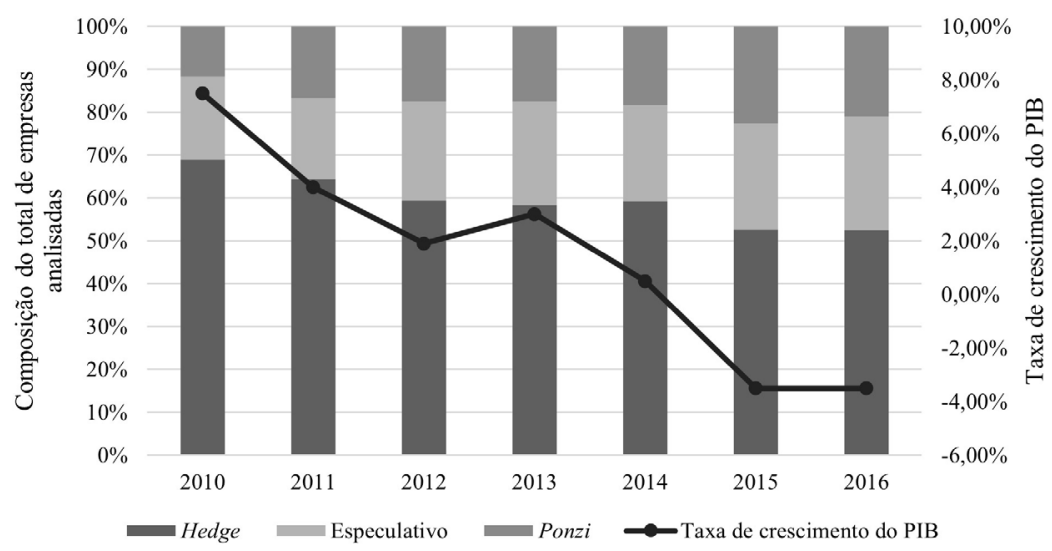

Fonte: Elaboração própria a partir do software Economatica e IBGE (2018).

Tabela 1 - Variação por perfil financeiro em comparação com o ano anterior ${ }^{14}$

\begin{tabular}{l|llllllll|lllllll}
\hline & \multicolumn{5}{|c|}{ Variação absoluta } & \multicolumn{5}{c}{ Variação em termos relativos } \\
\hline & 2011 & 2012 & 2013 & 2014 & 2015 & 2016 & $\begin{array}{l}2010- \\
2016\end{array}$ & 2011 & 2012 & 2013 & 2014 & 2015 & 2016 & $\begin{array}{l}2010- \\
2016\end{array}$ \\
\hline Hedge & -10 & -19 & -3 & 2 & -29 & -3 & -62 & $-4 \%$ & $-8 \%$ & $-1 \%$ & $1 \%$ & $-14 \%$ & $-2 \%$ & $-26 \%$ \\
Especulativo & 0 & 15 & 4 & -7 & 6 & 5 & 23 & $0 \%$ & $22 \%$ & $5 \%$ & $-8 \%$ & $8 \%$ & $6 \%$ & $34 \%$ \\
Ponzi & 19 & 3 & 0 & 3 & 13 & -7 & 31 & $46 \%$ & $5 \%$ & $0 \%$ & $5 \%$ & $20 \%$ & $-9 \%$ & $76 \%$ \\
\hline
\end{tabular}

Fonte: Elaboração própria a partir do software Economatica.

A análise do Gráfico 5 e da Tabela 1 permite esboçar algumas hipóteses a respeito da relação entre o período de desaceleração do ciclo econômico e o perfil financeiro das empresas da amostra. Nota-se que há uma queda no número de empresas hedge, sobretudo nos anos 2011 e 2012, quando, segundo Barbosa (2013), os efeitos das medidas restritivas do final do governo Lula e início do governo Dilma manifestavam-se com maior rigor. Ademais, há um aumento expressivo no número de empresas ponzi em 2011 (um acréscimo de 46\% em relação ao número de 2010), enquanto a variação mais expressiva do número de firmas especulativas se deu em 2012.

14 A soma das variações por ano não é nula porque o número de empresas da amostra varia ao longo do período analisado, por causa da entrada ou saída de empresas da base Economatica ou por problemas específicos nos dados de algumas empresas, que impossibilitaram a definição de seu perfil financeiro - essas empresas são colocadas como sem informação na Tabela 2. Apesar dessas diferenças, a manutenção de um grande número de empresas na amostra em todos os períodos permite que se analise o padrão geral para as empresas de capital aberto no Brasil no período. 
O melhor contexto econômico em 2013, ainda que não tenha levado a um aumento do número de empresas hedge, estancou o crescimento do número de firmas ponzi, de forma que houve um aumento modesto no número de empresas especulativas. Já em 2014, ano em que o crescimento do PIB volta a desacelerar fortemente, há uma diminuição no número de empresas especulativas e um aumento do número de empresas ponzi e hedge, de modo que não é possível concluir se houve piora ou melhora em relação ao ano anterior.

A recessão dos anos de 2015 e 2016 trouxe uma nova queda na participação de empresas com perfil hedge e um aumento do número de empresas com perfil especulativo ou ponzi. Assim, com uma queda da porcentagem de empresas em situação hedge de $69 \%$, em 2010, para 52\%, em 2016, e um aumento na porcentagem daquelas em situação ponzi de $12 \%$ para $21 \%$ no mesmo período, há indícios de que houve, no período de reversão do ciclo econômico, um aumento da fragilidade financeira das empresas abarcadas por nossa amostra.

O perfil ponzi foi o que apresentou a maior taxa média de variação anual ( $11 \%$ a.a.), seguido do perfil especulativo ( $5 \%$ a.a.), enquanto o perfil hedge decresceu, em média, $5 \%$ a.a. Comparando-se os valores de participação relativa de cada perfil entre 2010 e 2016, verifica-se que o número de empresas ponzi subiu $76 \%$, o de empresas especulativas subiu $35 \%$ e o de empresas hedge caiu $26 \%$.

Utilizando um índice alternativo de fragilidade financeira, Almeida, Novais e Rocha (2016) encontram resultados similares para o agregado da economia. Assim, observam uma redução no número absoluto de empresas de perfil hedge entre 2010 e 2015, acompanhada do aumento do número de empresas com perfil ponzi, apesar de encontrarem uma estabilidade maior no perfil especulativo. ${ }^{15}$ Uma evidência similar é apresentada pelo indicador proxy da fragilidade financeira da indústria da transformação e extrativa calculado por Corrêa, Lemos e Feijo (2017), que mostra maior fragilidade financeira do setor após a crise financeira internacional e, em especial, após 2010.

A Tabela 2 apresenta de forma mais detalhada a transição entre os anos 2010 e 2016 do perfil financeiro das empresas analisadas na amostra, de forma que é possível analisar o número de empresas que permaneceram na mesma situação ou mudaram de posição, além do saldo global para cada ano.

15 Vale relembrar, entretanto, que o perfil especulativo no trabalho de Almeida, Novais e Rocha (2016) é definido de forma distinta à definição do presente artigo, baseada em Bacic (1990). 
Tabela 2 - Transição das empresas dos setores selecionados entre 2010 e 2016

\begin{tabular}{|c|c|c|c|c|c|c|}
\hline & & \multicolumn{5}{|c|}{ Posição em 2016} \\
\hline & & Hedge & Especulativo & Ponzi & Sem informação & Total \\
\hline \multirow{5}{*}{$\begin{array}{l}\text { Posição em } \\
2010\end{array}$} & Hedge & 121 & 51 & 31 & 39 & 242 \\
\hline & Especulativo & 16 & 24 & 16 & 12 & 68 \\
\hline & Ponzi & 10 & 1 & 16 & 14 & 41 \\
\hline & $\begin{array}{l}\text { Sem } \\
\text { informação }\end{array}$ & 33 & 15 & 9 & & \\
\hline & Total & 180 & 91 & 72 & & \\
\hline
\end{tabular}

Fonte: Elaboração própria a partir do software Economatica.

Dentre as empresas hedge em 2010, 51 passaram para especulativas e 31, para ponzi, o que indica uma piora significativa do perfil financeiro das últimas. Ainda assim, cabe notar que grande parte das empresas hedge (50\% do total) continuaram nessa posição, de forma que há uma estabilidade maior nessa categoria em relação às demais. Há uma grande variabilidade no número de empresas com perfil especulativo, pois apenas 24 (35\% do total) mantiveram esse perfil, com uma melhora para 16 empresas, que se tornaram hedge, e piora para outras 16, que se tornaram ponzi. Essa variabilidade entre as empresas especulativas é característica de sua situação intermediária entre os perfis de fragilidade, de forma que pequenas mudanças podem levá-las a assumir um outro perfil financeiro.

Por fim, observa-se que as empresas ponzi apresentaram menor variabilidade ao longo do período do que as empresas especulativas, pois grande parte se manteve nessa posição (39\% do total), ainda que dez tenham apresentado uma melhora significativa, tornando-se hedge e uma tenha se tornado especulativa. Entretanto, das 14 empresas que eram ponzi, em 2010, e se apresentam como sem informação em 2016 (41\% do total de empresas ponzi em 2010), 13 estão como canceladas no software Economatica, o que indica que podem ter sido fechadas, compradas ou ter tido o capital fechado. ${ }^{16}$

A análise do perfil de fragilidade financeira para os 19 setores do software Economatica considerados nesta amostra sugere alguns padrões setoriais de fragilidade financeira para o período analisado. ${ }^{17}$ É possível observar que há alguns setores em que a dinâmica é bastante estável, com predominância de empresas hedge em todo o período (numa proporção maior ou igual a 70\%), como os setores de eletroeletrônicos, máquinas industriais, software e dados e transporte e serviços. Entretanto, mesmo nesse grupo mais estável, a recessão de 2015 e 2016 trouxe uma deterioração de seu perfil financeiro em relação ao que prevaleceu até 2014, com queda na proporção de empresas hedge no setor de transporte e servi-

16 É também possível que essas empresas tenham trocado de nome entre esses dois anos.

17 As informações setoriais estão disponíveis na Tabela 3 no Anexo A. 
ços de 81\%, em 2014, para 45\%, em 2016, e, no setor de máquinas industriais, de 100\%, em 2014, para 60\% em 2016 (ainda assim, ambos setores mantiveram baixo número de empresas ponzi).

Entre os setores que também apresentam uma dinâmica relativamente estável, mas com uma proporção menor de empresas hedge (acima de 50\% e até $70 \%$ ), estão os setores de comércio, energia elétrica, outros, petróleo e gás e química. Apesar desses setores terem mantido a participação de empresas hedge entre $50 \%$ e 70\%, houve uma importante deterioração nos setores de comércio, energia elétrica e outros, com diminuição do número de empresas hedge e aumento da participação de empresas especulativas e ponzi. No setor de petróleo e gás, as variações não foram tão expressivas, mas esse setor apresenta uma participação relativamente alta de empresas na situação ponzi (maior que $25 \%$ em todo o período). Por outro lado, o setor de química apresentou uma melhora ao longo do período, com aumento da proporção de empresas em situação hedge, a despeito da situação de deterioração econômica.

Em um nível intermediário, mas com uma dinâmica também estável, há um grupo de setores com empresas em que a participação de empresas hedge é ligeiramente menor que 50\%, mas no qual a participação conjunta de empresas hedge e especulativas é pelo menos igual a 60\%. Nesse grupo, há os setores de alimentos e bebidas, mineração, minerais não metálicos, papel e celulose, têxtil e veículos e peças. Com exceção da melhora do perfil financeiro das empresas ligadas aos setores de mineração e papel e celulose, houve deterioração em todos os outros setores, que também mostraram uma grande variabilidade.

Destaca-se a queda de empresas em situação hedge no setor de minerais não metálicos (de 100\%, em 2010, para 33\% em 2016) e no setor de veículos e peças (de 47\%, em 2010, para 36\% em 2016), além da expressiva piora no perfil financeiro das empresas do setor têxtil (entre 2010 e 2016, o aumento da proporção de empresas ponzi foi de $17 \%$ para $37 \%$ do total).

Os demais setores apresentam maior fragilidade financeira e maior volatilidade. Em particular, os setores de agro e pesca, construção, siderurgia e metalurgia e telecomunicações apresentam expressiva piora, com aumento do grau de fragilidade financeira. A deterioração foi mais significativa no caso do setor de construção (de 54\% de empresas hedge e 17\% empresas ponzi, em 2010, para 17\% empresas hedge e 58\% empresas ponzi em 2016), o que pode estar relacionado aos efeitos dos escândalos de corrupção no país, que afetaram o setor de modo negativo, e à redução do número de projetos de investimento público em infraestrutura no período. Contudo, também foi expressiva a deterioração dos setores de siderurgia e metalurgia e telecomunicações, pois ambos passaram de uma proporção de empresas hedge acima de 60\% e de empresas ponzi abaixo de 20\%, em 2010, para uma proporção de empresas hedge abaixo de 50\% e de empresas ponzi acima de 
45\% em 2016. Essa deterioração do perfil financeiro das empresas, saindo de uma proporção alta de empresas hedge para uma proporção alta de empresas ponzi, é especialmente preocupante, pois é mais difícil de ser revertida diante de um cenário de baixo crescimento.

\section{Considerações Finais}

O presente artigo analisou a evolução da fragilidade financeira de empresas não financeiras brasileiras de capital aberto no período de 2010 a 2016 a partir da abordagem minskyana. Como discutido, essa abordagem ajuda a entender o comportamento da fragilidade financeira da economia ao longo do ciclo econômico.

Em primeiro lugar, mostrou-se que durante o período analisado houve mudanças significativas no padrão de financiamento do investimento no país. Em especial, reduziu-se a proporção de recursos próprios e elevou-se o peso do financiamento externo. Esse processo coincidiu com o período de desaceleração do crescimento econômico a partir de 2011, bem como com a desvalorização cambial e pode ter contribuído para uma maior fragilidade financeira das empresas observadas, como também apontado por Almeida, Novais e Rocha (2016) e Corrêa, Lemos e Feijo (2017).

A análise da tipologia das firmas à la Minsky reforça essa análise. Os resultados obtidos indicam que houve uma deterioração no perfil financeiro das empresas de forma que diminuiu a proporção de empresas hedge e aumentou a proporção de empresas especulativas e ponzi, justamente em um período de desaceleração da economia. No entanto, é importante notar que a proporção de empresas ponzi nunca superou a proporção de empresas especulativas ou hedge para o total da economia, assim como a soma das empresas em situação ponzi e especulativa nunca superou o número de empresas hedge. Assim, ao menos no que diz respeito às empresas não financeiras de capital aberto, o artigo confirma a hipótese levantada por Corrêa, Lemos e Feijo (2017) de um aumento no número de empresas ponzi, mas é importante atentar-se à predominância de empresas hedge.

Ademais, ressalta-se a diversidade de padrões setoriais em termos de fragilidade financeira. Enquanto alguns setores apresentaram-se mais robustos às alterações sofridas pela economia no período (como os setores de eletroeletrônicos e software e dados), outros mostraram-se mais suscetíveis a essas alterações (agro e pesca, construção, siderurgia e metalurgia e telecomunicações). Esse quadro indica que mudanças no ciclo econômico e diferenças no padrão de financiamento do investimento atuam de forma distinta sobre a fragilidade financeira dos diferentes setores da economia brasileira. 


\section{Referências}

ALMEIDA, J. S. G et al. Padrões de financiamento das empresas: a experiência brasileira. In: CINTRA, M. A. M.; SILVA FILHO, E. B. (org.). Financiamento das corporações: perspectivas do desenvolvimento brasileiro. Brasília: IPEA, 2013.

ALMEIDA, J. S. G.; NOVAIS, L. F; ROCHA, M. A. A fragilização financeira das empresas não financeiras no Brasil pós-crise. Campinas: IE-Unicamp, 2016. (Texto para a Discussão).

BACIC, M. J. Fragilidade financeira e alavancagem: uma aplicação no segmento das maiores empresas do Brasil: 1980-1987. 1990. Dissertação. Instituto de Economia, Unicamp, 1990.

BANCO CENTRAL DO BRASIL. Sistema de séries temporais. 2018. Disponível em: https:// www3.bcb.gov.br/sgspub/localizarseries/localizarSeries.do?method=prepararTelaLocalizar Series. Acesso em: 07 jan. 2018.

BANCO NACIONAL DE DESENVOLVIMENTO ECONÔMICO E SOCIAL. Liuro verde: nossa história como ela é. Rio de Janeiro: BNDES, 2017.

BARBOSA, N. Dez anos de política econômica. In: SADER, E. (org.). 10 anos de governos pós-neoliberais no Brasil: Lula e Dilma. São Paulo: Boitempo; Rio de Janeiro: Flacso, 2013.

BASSETT, W. F. et al. Changes in bank lending standards and the macroeconomy. Journal of Monetary Economics, v. 62, p. 23-40, 2014.

BLECKER, R. A. The US economy since the crisis: slow recovery and secular stagnation. European Journal of Economics and Economic Policies, v. 13, n. 2, p. 203-214, 2016.

BODNAR, G. M.; MARSTON, R. C. Exchange rate exposure: a simple model. In: CHOI, J. J.; POWERS, M. R. (ed.). Global risk management: financial, operational, and insurance strategies. Bingley: Emerald, 2002.

BORIO, C.; FURFINE, C.; LOWE, P. Procyclicality of the financial system and financial stability: issues and policy options. BIS papers, 1 (March), p. 1-57, 2001.

CALLEN, T. What is gross domestic product? Finance 8 Development, v. 45, n. 4, p. 48-49, 2008.

CENTRO DE ESTUDOS DO MERCADO DE CAPITAIS (CEMEC). Endividamento das Empresas Brasileiras. 2016. Disponível em: http://ibmec.org.br/instituto/wp-content/ uploads/2014/10/31082016-NOTA-CEMEC-06-ENDIVIDAMENTO-EMPRESAS-FINAL-F. pdf. Acesso em: 08 fev. 2018.

CENTRO DE ESTUDOS DO MERCADO DE CAPITAIS (CEMEC). Relatório trimestral de financiamento dos investimentos no Brasil. Rio de Janeiro, 2017a. Disponível em: http://ibmec. org.br/instituto/wp-content/uploads/2014/10/NOTA-CEMEC-05-2017-PADRAO-DE-FINANCIAMENTO-DOS-INVESTIMENTOS.pdf. Acesso em: 04 mar. 2018. 
CENTRO DE ESTUDOS DO MERCADO DE CAPITAIS (CEMEC). Indicadores de endividamento e capacidade de pagamento das empresas não financeiras. Rio de Janeiro: 2017b. Disponível em: http://ibmec.org.br/instituto/wp-content/uploads/2014/10/NOTA-CEMEC06-COMPLETO.pdf. Acesso em: 04 mar. 2018.

CORREAA, M. F.; LEMOS, P.M.; FEIJO, C. Financeirização, empresas não financeiras e o ciclo econômico recente da economia brasileira. Economia e Sociedade, v. 26, número especial, p. 1127-1148, 2017.

IBGE. Contas nacionais trimestrais. 2018. Disponível em: https://sidra.ibge.gov.br/home/cnt/ brasil. Acesso em: 07 fev. 2018.

KALECKI, M. As equações marxistas de reprodução e a economia moderna. In: MIGLIOLI, J. (org.). Crescimento e ciclo das economias capitalistas. São Paulo: Hucitec, 1983.

LAVOIE, M.; SECCARECCIA, M. Minsky's financial fragility hypothesis: a missing macroeconomic link? In: BELLOFIORE, R.; FERRI, P. (ed.). Financial fragility and investment in the capitalist economy: the economic legacy of Hyman Minsky. Cheltenham: Edward Elgar, 2001.

LOURENÇO, A. O pensamento de Hyman P. Minsky: alterações de percurso e atualidade. Economia e Sociedade, Campinas, v. 15, n. 3, p. 445-474, 2006.

MELLO, G.; ROSSI, P. Do industrialismo à austeridade: a política macro dos governos Dilma. Instituto de Economia/Unicamp, 2017. (Texto para Discussão, $n^{\circ} .309$ )

MINSKY, H. P. Stabilizing an unstable economy. New York: McGraw Hill, 2008.

MINSKY, H. P. The financial instability hypothesis. The Jerome Leuy Economics Institute Working Paper, n. 74, 1992.

MINSKY, H. P. Integração financeira e política monetária. Economia e Sociedade, n. 3, dez. 1994.

PAULA, L. F. de. Porque a grande crise não aconteceu. Valor Econômico, 2017. Disponível em: http:/www.valor.com.br/opiniao/4831026/porque-grande-crise-nao-aconteceu. Acesso em: 08 fev. 2018.

REZENDE, F. Financial fragility, instability and the Brazilian crisis: a Keynes-Minsky-Godley approach. Geneva: MINDS, 2016. (Discussion paper, 1) 


\section{Anexo A - Análise Setorial}

Tabela 3 - Perfil financeiro por setor: número de empresas e participação (2010 a 2016)

\begin{tabular}{|c|c|c|c|c|c|c|c|c|}
\hline & & 2010 & 2011 & 2012 & 2013 & 2014 & 2015 & 2016 \\
\hline \multirow{6}{*}{ Agro e pesca } & Hedge & 3 & 2 & 2 & 1 & 2 & 2 & 1 \\
\hline & Participação & $60 \%$ & $40 \%$ & $40 \%$ & $25 \%$ & $50 \%$ & $50 \%$ & $25 \%$ \\
\hline & Especulativo & 1 & 1 & 2 & 3 & 1 & 1 & 1 \\
\hline & Participação & $20 \%$ & $20 \%$ & $40 \%$ & $75 \%$ & $25 \%$ & $25 \%$ & $25 \%$ \\
\hline & Ponzi & 1 & 2 & 1 & 0 & 1 & 1 & 2 \\
\hline & Participação & $20 \%$ & $40 \%$ & $20 \%$ & $0 \%$ & $25 \%$ & $25 \%$ & $50 \%$ \\
\hline \multirow{6}{*}{ Alimentos e bebidas } & Hedge & 10 & 8 & 9 & 6 & 8 & 7 & 6 \\
\hline & Participação & $59 \%$ & $44 \%$ & $47 \%$ & $35 \%$ & $47 \%$ & $41 \%$ & $43 \%$ \\
\hline & Especulativo & 5 & 6 & 6 & 9 & 7 & 7 & 7 \\
\hline & Participação & $29 \%$ & $33 \%$ & $32 \%$ & $53 \%$ & $41 \%$ & $41 \%$ & $50 \%$ \\
\hline & Ponzi & 2 & 4 & 4 & 2 & 2 & 3 & 1 \\
\hline & Participação & $12 \%$ & $22 \%$ & $21 \%$ & $12 \%$ & $12 \%$ & $18 \%$ & $7 \%$ \\
\hline \multirow{6}{*}{ Comércio } & Hedge & 16 & 14 & 14 & 13 & 12 & 14 & 14 \\
\hline & Participação & $76 \%$ & $67 \%$ & $67 \%$ & $62 \%$ & $57 \%$ & $67 \%$ & $64 \%$ \\
\hline & Especulativo & 3 & 4 & 4 & 5 & 5 & 4 & 3 \\
\hline & Participação & $14 \%$ & $19 \%$ & $19 \%$ & $24 \%$ & $24 \%$ & $19 \%$ & $14 \%$ \\
\hline & Ponzi & 2 & 3 & 3 & 3 & 4 & 3 & 5 \\
\hline & Participação & $10 \%$ & $14 \%$ & $14 \%$ & $14 \%$ & $19 \%$ & $14 \%$ & $23 \%$ \\
\hline \multirow{6}{*}{ Construção } & Hedge & 13 & 9 & 6 & 8 & 5 & 5 & 4 \\
\hline & Participação & $54 \%$ & $38 \%$ & $25 \%$ & $33 \%$ & $21 \%$ & $21 \%$ & $17 \%$ \\
\hline & Especulativo & 7 & 8 & 8 & 10 & 9 & 10 & 6 \\
\hline & Participação & $29 \%$ & $33 \%$ & $33 \%$ & $42 \%$ & $38 \%$ & $42 \%$ & $25 \%$ \\
\hline & Ponzi & 4 & 7 & 10 & 6 & 10 & 9 & 14 \\
\hline & Participação & $17 \%$ & $29 \%$ & $42 \%$ & $25 \%$ & $42 \%$ & $38 \%$ & $58 \%$ \\
\hline \multirow{6}{*}{ Eletroeletrônicos } & Hedge & 5 & 5 & 5 & 5 & 5 & 4 & 3 \\
\hline & Participação & $83 \%$ & $83 \%$ & $83 \%$ & $83 \%$ & $83 \%$ & $80 \%$ & $75 \%$ \\
\hline & Especulativo & 1 & 0 & 1 & 0 & 0 & 0 & 0 \\
\hline & Participação & $17 \%$ & $0 \%$ & $17 \%$ & $0 \%$ & $0 \%$ & $0 \%$ & $0 \%$ \\
\hline & Ponzi & 0 & 1 & 0 & 1 & 1 & 1 & 1 \\
\hline & Participação & $0 \%$ & $17 \%$ & $0 \%$ & $17 \%$ & $17 \%$ & $20 \%$ & $25 \%$ \\
\hline \multirow{6}{*}{ Energia elétrica } & Hedge & 39 & 42 & 36 & 34 & 38 & 29 & 31 \\
\hline & Participação & $76 \%$ & $75 \%$ & $65 \%$ & $61 \%$ & $68 \%$ & $53 \%$ & $56 \%$ \\
\hline & Especulativo & 9 & 10 & 13 & 13 & 12 & 23 & 22 \\
\hline & Participação & $18 \%$ & $18 \%$ & $24 \%$ & $23 \%$ & $21 \%$ & $42 \%$ & $40 \%$ \\
\hline & Ponzi & 3 & 4 & 6 & 9 & 6 & 3 & 2 \\
\hline & Participação & $6 \%$ & $7 \%$ & $11 \%$ & $16 \%$ & $11 \%$ & $5 \%$ & $4 \%$ \\
\hline
\end{tabular}

Continua... 


\begin{tabular}{|c|c|c|c|c|c|c|c|c|}
\hline & & 2010 & 2011 & 2012 & 2013 & 2014 & 2015 & 2016 \\
\hline \multirow{6}{*}{ Máquinas industriais } & Hedge & 4 & 4 & 3 & 3 & 4 & 3 & 3 \\
\hline & Participação & $100 \%$ & $100 \%$ & $75 \%$ & $75 \%$ & $100 \%$ & $75 \%$ & $60 \%$ \\
\hline & Especulativo & 0 & 0 & 1 & 1 & 0 & 1 & 2 \\
\hline & Participação & $0 \%$ & $0 \%$ & $25 \%$ & $25 \%$ & $0 \%$ & $25 \%$ & $40 \%$ \\
\hline & Ponzi & 0 & 0 & 0 & 0 & 0 & 0 & 0 \\
\hline & Participação & $0 \%$ & $0 \%$ & $0 \%$ & $0 \%$ & $0 \%$ & $0 \%$ & $0 \%$ \\
\hline \multirow{6}{*}{ Mineração } & Hedge & 2 & 3 & 4 & 3 & 2 & 3 & 5 \\
\hline & Participação & $40 \%$ & $50 \%$ & $67 \%$ & $50 \%$ & $40 \%$ & $60 \%$ & $100 \%$ \\
\hline & Especulativo & 2 & 1 & 1 & 1 & 1 & 0 & 0 \\
\hline & Participação & $40 \%$ & $17 \%$ & $17 \%$ & $17 \%$ & $20 \%$ & $0 \%$ & $0 \%$ \\
\hline & Ponzi & 1 & 2 & 1 & 2 & 2 & 2 & 0 \\
\hline & Participação & $20 \%$ & $33 \%$ & $17 \%$ & $33 \%$ & $40 \%$ & $40 \%$ & $0 \%$ \\
\hline \multirow{6}{*}{$\begin{array}{l}\text { Minerais não } \\
\text { metálicos }\end{array}$} & Hedge & 2 & 2 & 2 & 1 & 1 & 1 & 1 \\
\hline & Participação & $100 \%$ & $67 \%$ & $67 \%$ & $33 \%$ & $33 \%$ & $33 \%$ & $33 \%$ \\
\hline & Especulativo & 0 & 1 & 1 & 2 & 2 & 2 & 2 \\
\hline & Participação & $0 \%$ & $33 \%$ & $33 \%$ & $67 \%$ & $67 \%$ & $67 \%$ & $67 \%$ \\
\hline & Ponzi & 0 & 0 & 0 & 0 & 0 & 0 & 0 \\
\hline & Participação & $0 \%$ & $0 \%$ & $0 \%$ & $0 \%$ & $0 \%$ & $0 \%$ & $0 \%$ \\
\hline \multirow{6}{*}{ Outros } & Hedge & 72 & 70 & 67 & 69 & 65 & 59 & 59 \\
\hline & Participação & $77 \%$ & $72 \%$ & $67 \%$ & $70 \%$ & $65 \%$ & $61 \%$ & $61 \%$ \\
\hline & Especulativo & 11 & 10 & 13 & 15 & 20 & 13 & 16 \\
\hline & Participação & $12 \%$ & $10 \%$ & $13 \%$ & $15 \%$ & $20 \%$ & $13 \%$ & $17 \%$ \\
\hline & Ponzi & 11 & 17 & 20 & 15 & 15 & 25 & 21 \\
\hline & Participação & $12 \%$ & $18 \%$ & $20 \%$ & $15 \%$ & $15 \%$ & $26 \%$ & $22 \%$ \\
\hline \multirow{6}{*}{ Papel e celulose } & Hedge & 2 & 2 & 2 & 2 & 3 & 2 & 4 \\
\hline & Participação & $40 \%$ & $40 \%$ & $40 \%$ & $40 \%$ & $60 \%$ & $40 \%$ & $80 \%$ \\
\hline & Especulativo & 2 & 2 & 3 & 3 & 2 & 2 & 1 \\
\hline & Participação & $40 \%$ & $40 \%$ & $60 \%$ & $60 \%$ & $40 \%$ & $40 \%$ & $20 \%$ \\
\hline & Ponzi & 1 & 1 & 0 & 0 & 0 & 1 & 0 \\
\hline & Participação & $20 \%$ & $20 \%$ & $0 \%$ & $0 \%$ & $0 \%$ & $20 \%$ & $0 \%$ \\
\hline \multirow{6}{*}{ Petróleo e gás } & Hedge & 4 & 4 & 4 & 5 & 5 & 4 & 5 \\
\hline & Participação & $67 \%$ & $57 \%$ & $57 \%$ & $63 \%$ & $63 \%$ & $57 \%$ & $63 \%$ \\
\hline & Especulativo & 0 & 1 & 1 & 1 & 1 & 0 & 1 \\
\hline & Participação & $0 \%$ & $14 \%$ & $14 \%$ & $13 \%$ & $13 \%$ & $0 \%$ & $13 \%$ \\
\hline & Ponzi & 2 & 2 & 2 & 2 & 2 & 3 & 2 \\
\hline & Participação & $33 \%$ & $29 \%$ & $29 \%$ & $25 \%$ & $25 \%$ & $43 \%$ & $25 \%$ \\
\hline \multirow{6}{*}{ Química } & Hedge & 7 & 4 & 5 & 5 & 7 & 6 & 7 \\
\hline & Participação & $58 \%$ & $44 \%$ & $56 \%$ & $56 \%$ & $64 \%$ & $60 \%$ & $70 \%$ \\
\hline & Especulativo & 4 & 3 & 3 & 2 & 2 & 1 & 2 \\
\hline & Participação & $33 \%$ & $33 \%$ & $33 \%$ & $22 \%$ & $18 \%$ & $10 \%$ & $20 \%$ \\
\hline & Ponzi & 1 & 2 & 1 & 2 & 2 & 3 & 1 \\
\hline & Participação & $8 \%$ & $22 \%$ & $11 \%$ & $22 \%$ & $18 \%$ & $30 \%$ & $10 \%$ \\
\hline
\end{tabular}

Continua... 
Conclusão.

\begin{tabular}{|c|c|c|c|c|c|c|c|c|}
\hline & & 2010 & 2011 & 2012 & 2013 & 2014 & 2015 & 2016 \\
\hline \multirow{6}{*}{$\begin{array}{l}\text { Siderurgia e } \\
\text { metalurgia }\end{array}$} & Hedge & 14 & 12 & 10 & 11 & 13 & 8 & 6 \\
\hline & Participação & $78 \%$ & $67 \%$ & $59 \%$ & $61 \%$ & $72 \%$ & $42 \%$ & $32 \%$ \\
\hline & Especulativo & 3 & 4 & 5 & 4 & 3 & 6 & 4 \\
\hline & Participação & $17 \%$ & $22 \%$ & $29 \%$ & $22 \%$ & $17 \%$ & $32 \%$ & $21 \%$ \\
\hline & Ponzi & 1 & 2 & 2 & 3 & 2 & 5 & 9 \\
\hline & Participação & $6 \%$ & $11 \%$ & $12 \%$ & $17 \%$ & $11 \%$ & $26 \%$ & $47 \%$ \\
\hline \multirow{6}{*}{ Software e dados } & Hedge & 3 & 4 & 4 & 5 & 5 & 5 & 5 \\
\hline & Participação & $100 \%$ & $100 \%$ & $100 \%$ & $100 \%$ & $100 \%$ & $100 \%$ & $100 \%$ \\
\hline & Especulativo & 0 & 0 & 0 & 0 & 0 & 0 & 0 \\
\hline & Participação & $0 \%$ & $0 \%$ & $0 \%$ & $0 \%$ & $0 \%$ & $0 \%$ & $0 \%$ \\
\hline & Ponzi & 0 & 0 & 0 & 0 & 0 & 0 & 0 \\
\hline & Participação & $0 \%$ & $0 \%$ & $0 \%$ & $0 \%$ & $0 \%$ & $0 \%$ & $0 \%$ \\
\hline \multirow{6}{*}{ Telecomunicações } & Hedge & 11 & 10 & 8 & 6 & 2 & 4 & 5 \\
\hline & Participação & $61 \%$ & $59 \%$ & $53 \%$ & $38 \%$ & $15 \%$ & $33 \%$ & $45 \%$ \\
\hline & Especulativo & 4 & 3 & 3 & 1 & 1 & 0 & 1 \\
\hline & Participação & $22 \%$ & $18 \%$ & $20 \%$ & $6 \%$ & $8 \%$ & $0 \%$ & $9 \%$ \\
\hline & Ponzi & 3 & 4 & 4 & 9 & 10 & 8 & 5 \\
\hline & Participação & $17 \%$ & $24 \%$ & $27 \%$ & $56 \%$ & $77 \%$ & $67 \%$ & $45 \%$ \\
\hline \multirow{6}{*}{ Têxtil } & Hedge & 13 & 13 & 11 & 11 & 11 & 8 & 7 \\
\hline & Participação & $57 \%$ & $54 \%$ & $48 \%$ & $52 \%$ & $50 \%$ & $38 \%$ & $37 \%$ \\
\hline & Especulativo & 6 & 6 & 7 & 6 & 5 & 5 & 5 \\
\hline & Participação & $26 \%$ & $25 \%$ & $30 \%$ & $29 \%$ & $23 \%$ & $24 \%$ & $26 \%$ \\
\hline & Ponzi & 4 & 5 & 5 & 4 & 6 & 8 & 7 \\
\hline & Participação & $17 \%$ & $21 \%$ & $22 \%$ & $19 \%$ & $27 \%$ & $38 \%$ & $37 \%$ \\
\hline \multirow{6}{*}{ Transporte e serviços } & Hedge & 14 & 14 & 16 & 15 & 17 & 12 & 9 \\
\hline & Participação & $70 \%$ & $74 \%$ & $84 \%$ & $71 \%$ & $81 \%$ & $60 \%$ & $45 \%$ \\
\hline & Especulativo & 4 & 3 & 3 & 5 & 4 & 6 & 11 \\
\hline & Participação & $20 \%$ & $16 \%$ & $16 \%$ & $24 \%$ & $19 \%$ & $30 \%$ & $55 \%$ \\
\hline & Ponzi & 2 & 2 & 0 & 1 & 0 & 2 & 0 \\
\hline & Participação & $10 \%$ & $11 \%$ & $0 \%$ & $5 \%$ & $0 \%$ & $10 \%$ & $0 \%$ \\
\hline \multirow{6}{*}{ Veículos e peças } & Hedge & 8 & 10 & 5 & 7 & 7 & 7 & 5 \\
\hline & Participação & $47 \%$ & $59 \%$ & $29 \%$ & $41 \%$ & $47 \%$ & $50 \%$ & $36 \%$ \\
\hline & Especulativo & 6 & 5 & 8 & 6 & 5 & 5 & 7 \\
\hline & Participação & $35 \%$ & $29 \%$ & $47 \%$ & $35 \%$ & $33 \%$ & $36 \%$ & $50 \%$ \\
\hline & Ponzi & 3 & 2 & 4 & 4 & 3 & 2 & 2 \\
\hline & Participação & $18 \%$ & $12 \%$ & $24 \%$ & $24 \%$ & $20 \%$ & $14 \%$ & $14 \%$ \\
\hline \multirow{7}{*}{ Total } & Hedge & 242 & 232 & 213 & 210 & 212 & 183 & 180 \\
\hline & Participação & $69 \%$ & $64 \%$ & $59 \%$ & $58 \%$ & $59 \%$ & $53 \%$ & $52 \%$ \\
\hline & Especulativo & 68 & 68 & 83 & 87 & 80 & 86 & 91 \\
\hline & Participação & $19 \%$ & $19 \%$ & $23 \%$ & $24 \%$ & $22 \%$ & $25 \%$ & $27 \%$ \\
\hline & Ponzi & 41 & 60 & 63 & 63 & 66 & 79 & 72 \\
\hline & Participação & $12 \%$ & $17 \%$ & $18 \%$ & $18 \%$ & $18 \%$ & $23 \%$ & $21 \%$ \\
\hline & Total & 351 & 360 & 359 & 360 & 358 & 348 & 343 \\
\hline
\end{tabular}

Fonte: Elaboração própria a partir do software Economatica. 
Autor correspondente:

Lilian N. Rolim

E-mail: lilian.rolim@gmail.com
Recebido em: 25/06/2018.

Aceito em: 05/02/2019.

(cc) $\mathbf{B Y}$ 